\title{
Pulmonary hypertension: the state of the art
}

\author{
Konstantinos Dimopoulos, Carla Favoccia
}

Adult Congenital Heart Centre and National Centre for Pulmonary Hypertension, National Heart and Lung Institute, Royal Brompton Hospital, Imperial College, London, UK

\begin{abstract}
Pulmonary hypertension $(\mathrm{PH})$ is a hemodynamic and pathophysiological condition defined as an increase in mean pulmonary arterial pressure of $25 \mathrm{mmHg}$ or more at rest assessed by right heart catheterisation. It is a progressive disease characterized by high mortality and morbidity. Current PH guidelines suggest that patients with PH should be cared for in dedicated specialist centres, with expertise and resources available to provide high quality care to this fragile population. In this review, we focus on the clinical manifestations, diagnostic algorithm, risk assessment and therapeutic strategies for PH. We also provide an overview of the organisation of PH services in United Kingdom, including designation of expert centres, national audit and steps to ensure the quality and financial viability of $\mathrm{PH}$ care.
\end{abstract}

\section{Introduction}

Pulmonary hypertension $(\mathrm{PH})$ is a progressive and debilitating condition, defined as an increase in mean pulmonary artery pressure (mPAP) $\geq 25 \mathrm{mmHg}$ at rest, measured by right heart catheterization (RHC). It is associated with a range of underlying aetiologies, most commonly chronic left-sided cardiac disease or lung disease. In recent years, chronic thromboembolic disease $(\mathrm{CTEPH})$ is increasingly recognised as a common cause of $\mathrm{PH}$. This, and other rare forms of $\mathrm{PH}$, including idiopathic pulmonary arterial hypertension (PAH) and PAH related to connective

Correspondence: Konstantinos Dimopoulos, Adult Congenital Heart Centre and Pulmonary Hypertension, Royal Brompton and Harefield NHS Foundation Trust, Sydney Street, SW3 6NP London, UK.

Tel.: +44.2073528121 ext. 2771 - Fax: +44.207351.8629.

E-mail: k.dimopoulos02@gmail.com

Key words: Pulmonary hypertension; national audit; expertise centres.

Conflict of interest: Dr. Dimopoulos has received unrestricted educational, travel or research grants from Bayer, Pfizer, Actelion and GSK. Dr Dimopoulos has acted as a consultant to Pfizer, Actelion and GSK.

Received for publication: 10 June 2018.

Accepted for publication: 16 July 2018.

This work is licensed under a Creative Commons Attribution NonCommercial 4.0 License (CC BY-NC 4.0).

CCopyright K. Dimopoulos and C. Favoccia, 2018

Licensee PAGEPress, Italy

Italian Journal of Medicine 2018; 12:159-170

doi:10.4081/itjm.2018.1067 tissue disease (CTD) and congenital heart disease (CHD) have received significant attention, with numerous randomised trials establishing the role of $\mathrm{PAH}$ therapies and changing the landscape of $\mathrm{PH}$.

$\mathrm{PH}$ is characterized by breathlessness, fatigue and psychological distress. The diagnosis of $\mathrm{PH}$ is often overlooked, as the typical signs and symptoms of PH are non-specific, and are similar to other more common conditions, such as asthma, chronic obstructive pulmonary disease (COPD) and heart failure. Delays in the diagnosis and management of $\mathrm{PH}$ can be detrimental and should be avoided through education and increased awareness of the condition, combined with early referral to expert centres. ${ }^{1}$

\section{The classification of pulmonary hypertension}

\section{Hemodynamic definition}

From a hemodynamic point of view, PH can be classified on the basis of the pulmonary artery wedge pressure (PAWP) into pre-capillary (PAWP $\leq 15 \mathrm{mmHg}$ ) or post-capillary (PAWP $>15 \mathrm{mmHg}$, Table 1 ). In the latest classification, post-capillary $\mathrm{PH}$ is distinguished into isolated or combined pre and post-capillary, based on pulmonary vascular resistance (cut-off of $3 \mathrm{WU}$ ) and the diastolic pressure gradient (cut-off of $7 \mathrm{mmHg}$ ). RHC, thus, remains essential for the diagnostic workup of $\mathrm{PH}$ patients and for deciding management. ${ }^{1}$

Examples of post-capillary $\mathrm{PH}$ include patients with severe systolic or diastolic left ventricle (LV) dysfunction or valve disease (e.g. mitral stenosis). When post-capillary $\mathrm{PH}$ is long-standing, or other causes of $\mathrm{PH}$ are present, a precapillary component can develop, resulting in combined pre- and postcapillary PH.

Cardiac catheterisation is essential for establishing 
the diagnosis of $\mathrm{PH}$, but requires significant expertise, which is occasionally lost in busy interventional cardiology laboratories that focus on ischemic heart disease. Small errors in measuring PAWP can lead to an erroneous classification of patients. This may be related to significant respiratory swing, suboptimal wedging (over or under-wedging), calibration and damping. Error can also be introduced when estimating cardiac output, ideally using either the direct Fick formula (with measurement of oxygen consumption in the cardiac catheter laboratory), thermodilution, or cardiac magnetic resonance (in hybrid laboratories). ${ }^{2}$ Operators should be well aware of the limitations and potential pitfalls of each technique (e.g. thermodilution is not recommended in patients with intracardiac shunts). Finally, few laboratories are able to provide vasoreactivity testing, which is typically performed using inhaled nitric oxide or other pulmonary vasodilators. RHC is also important in assessing the severity of hemodynamic impairment, for risk stratification, to assess the effect of treatment and the progression of disease. Repeat cardiac catheterisation is, therefore, the rule for most PH patients, especially those who are deemed candidates for specific therapies. ${ }^{1}$

Some aspects of the $\mathrm{PH}$ definition and classification are still debated by experts. It is recognised that patients with borderline mean PA pressure between 21-24 mmHg should be monitored carefully, as studies have suggested that a mPAP $>20$ $\mathrm{mmHg}$ exceeds the upper limit of normal (normal mPAP $14 \pm 3.3 \mathrm{mmHg}$ ) and patients with borderline $\mathrm{PH}$ have a worse prognosis compared to patients with $\mathrm{mPAP} \leq 20 \mathrm{mmHg} \cdot{ }^{1,3}$

\section{Clinical classification}

The current international PH classification divides $\mathrm{PH}$ into 5 groups, encompassing multiple clinical conditions, which share similarities in presentation, pathological findings, haemodynamic characteristics and treatment strategy. This categorization is now accepted worldwide and used in clinical practice (Table 2).

\section{Group 1}

$\mathrm{PAH}$, is a disease characterized by progressive remodelling of the distal pulmonary arteries, resulting in the loss of vascular cross-sectional area and elevated pulmonary vascular resistance (PVR). PAH has different aetiologies, leading to pre-capillary pulmonary hypertension. It is termed idiopathic when no causative factors are identified and heritable when it has a possible genetic transmission., $4.5 \mathrm{PAH}$ can be also induced by drugs or toxins, or can be associated with conditions, such as CTD, CHD, portal hypertension and HIV infection.

Every year, new genes associated with PAH are discovered, reiterating the importance of genetic screening in tertiary centres. Moreover, new drugs and toxins responsible for the development of PAH have been discovered in recent years: e.g. dasanatib is a chemotherapy drug that can induce remodelling and capillary proliferation in the pulmonary circulation, but these changes may be reversed when it is stopped. Anorexigens, such as aminorex, fenfluramine and benfluorex are the first class of medications recognized to cause PAH. Although, most of these medications have now been withdrawn worldwide, they remain important, not only from a historical perspective, but because they emphasise the role of serotonin metabolism in the pathogenesis of $\mathrm{PAH} .{ }^{5}$

Group 1 also includes pulmonary veno-occlusive disease (PVOD, Group 1') and the persistent pulmonary hypertension of the newborn (Group 1"). PVOD is rare and can resemble idiopathic PAH in terms of clinical presentation and haemodynamics (raised mPAP with a normal PAWP); however, its management differs significantly, requiring early referral to lung transplantation. ${ }^{1}$

\section{Group 2}

Group 2 is characterized by PH secondary to left heart disease. The most frequent reason is diastolic dysfunction of the left ventricle, typically present in older patients with risk factors, such as diabetes mellitus, hypertension, hyperlipidaemia and ischemic heart disease. ${ }^{6}$ Group 2 PH is typically postcapillary,

Table 1. Hemodynamic classification of pre and post capillary pulmonary hypertension.

\begin{tabular}{|c|c|c|c|c|c|}
\hline & $\begin{array}{c}\text { mPAP } \\
\geq 25 \mathrm{mmHg}\end{array}$ & $\begin{array}{c}\text { PAWP } \\
\leq 15 \mathrm{mmHg}\end{array}$ & $\begin{array}{c}\text { PAWP } \\
>15 \mathrm{mmHg}\end{array}$ & $\begin{array}{c}\text { DPG }<7 \text { and/or } \\
\text { PVR } \leq 3 \text { WU }\end{array}$ & $\begin{array}{c}\text { DPG } \geq 7 \text { and } / \text { or } \\
\text { PVR }>3 \text { WU }\end{array}$ \\
\hline $\mathrm{PH}$ & $\bullet$ & & & & \\
\hline Pre-capillary PH & $\bullet$ & $\bullet$ & & & \\
\hline Isolated post-capillary $\mathrm{PH}$ & $\bullet$ & & $\bullet$ & $\bullet$ & \\
\hline Combined post-capillary and pre-capillary $\mathrm{PH}$ & $\bullet$ & & $\bullet$ & & $\bullet$ \\
\hline
\end{tabular}

mPAP, mean pulmonary artery pressure; PAWP, pulmonary artery wedge pressure; DPG, diastolic pressure gradient (diastolic pulmonary artery pressure - mean PAWP); PVR, pulmonary vascular resistance; PH, pulmonary hypertension. 
but a reactive precapillary component may develop (combined pre and post-capillary PH, Table 1). In patients with multiple comorbidities, pre and postcapillary PH may coexist (e.g. in a patient with chronic thromboembolic disease or scleroderma and left ventricular diastolic dysfunction), complicating management. ${ }^{1}$

There is still debate on the optimal state of hydration at which patients should be hemodynamically assessed. Patients with left heart disease who have been fasting for several hours before cardiac catheterisation, may have a resting PAWP $\leq 15 \mathrm{mmHg}$ and could be misdiagnosed as precapillary PH. In such cases, and when there is clear suspicion of a postcapillary component to the $\mathrm{PH}$, some centres suggest fluid or exercise challenge during the catheter assessment. However, there is still insufficient evidence to guide the interpretation of such challenges and hence, to date, there are no clear recommendations in the $\mathrm{PH}$ guidelines.

Table 2. Clinical classification of pulmonary hypertension.

\begin{tabular}{l} 
1. Pulmonary arterial hypertension \\
\hline 1.1 Idiopathic \\
\hline 1.2 Heritable \\
1.2.1 BMPR 2 mutation \\
1.2.2 Other mutations \\
\hline 1.3 Drugs and toxins induced \\
\hline 1.4 Associated with: \\
1.4.1 Connective tissue disease \\
1.4.2 HIV infection \\
1.4.3 Portal hypertension \\
1.4.5 Congenital heart disease
\end{tabular}

2. Pulmonary hypertension due to left heart disease

2.1 Left ventricular systolic dysfunction

2.2 Left ventricular diastolic dysfunction

2.3 Valvular disease

2.4 Congenital/acquired left heart inflow/outflow tract obstruction and congenital cardiomyopathies

2.5 Congenital/acquired pulmonary veins stenosis hypertension due to lung disease

4. Chronic thromboembolic pulmonary hypertension and other pulmonary artery obstructions

4.1 Chronic thromboembolic pulmonary hypertension

4.2 Other pulmonary artery obstructions

4.2.1 Angiosarcoma

4.2.2 Other intravascular tumors

4.2.3 Arteritis

4.2.4 Congenital pulmonary arteries stenosis

4.2.5 Parasites (hydatidosis)

\section{Group 3}

Group 3 includes patients with lung disease and PH: COPD and interstitial lung disease, mixed restrictive/obstructive, alveolar hypoxia and developmental disorders, such as congenital or bronchopulmonary dysplasia. Because exertional dyspnea is the most common symptom associated with both $\mathrm{PH}$ and lung disease, the presence of coexisting PH is easily overlooked. ${ }^{7}$ The pathogenesis of $\mathrm{PH}$ in this group is multifactorial and may result from chronic hypoxic pulmonary vasoconstriction and vascular remodelling. Other possible mechanisms include vascular obstruction or destruction associated with progressive parenchymal fibrosis, vascular inflammation, perivascular fibrosis and thrombotic angiopathy. To date, there is no convincing evidence from randomised trials on the use of PAH therapies for patients who belong to Group $3 .^{8}$ These patients have a very poor outcome, and there is an urgent need to identify new management strategies.

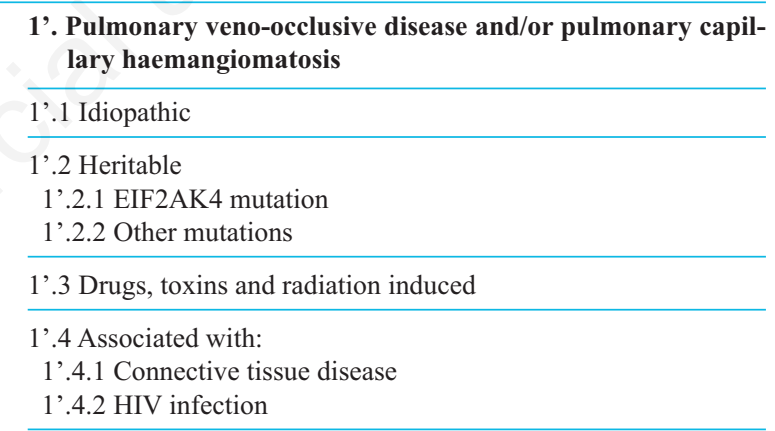

1". Persistent pulmonary hypertension of the newborn

3. Pulmonary hypertension due to lung diseases and/or hypoxia

3.1 Chronic obstructive pulmonary disease

3.2 Interstitial lung disease

3.3 Other pulmonary diseases with mixed restrictive and obstructive pattern

3.4 Sleep-disordered breathing

3.5 Alveolar hypoventilation disorders

3.6 Chronic exposure to high altitude

3.7 Developmental lung diseases

5. Pulmonary hypertension with unclear and/or multifactorial mechanisms

5.1 Haematological disorders

5.2 Systemic disorders

5.3 Metabolic disorders

5.4 Others 


\section{Group 4}

Group 4 includes patients with CTEPH and other conditions causing obstruction of the pulmonary arteries (e.g. angiosarcoma, intravascular tumors, arteritis, congenital pulmonary artery stenosis). ${ }^{9}$ $\mathrm{CTEPH}$ is a rare and insidious complication of pulmonary embolism, due to unresolved, organised pulmonary artery thrombi. It is often diagnosed late and often occurs in patients with no history of symptomatic venous thromboembolism.

A V/Q scan to exclude CTEPH is recommended for all $\mathrm{PH}$ patients at the time of referral to a specialist centre. The treatment of choice is pulmonary endarterectomy (PEA), effectively lowering the pulmonary vascular resistance and significantly improving outcome. However, surgery is not possible in around a third of cases, who may benefit from PAH therapy or balloon pulmonary angioplasty. ${ }^{10-12}$

\section{Group 5}

Group 5 includes PH of unclear and/or multifactorial mechanisms (Table 2) and will not be discussed in this paper.

\section{Diagnostic algorithm}

Dyspnoea, syncope on effort, angina and fatigue, with progressive limitation of exercise capacity are typical symptoms related to $\mathrm{PH}$, but lack specificity, as they are common in other cardiovascular and respiratory disorders. Therefore, clinical suspicion and awareness of $\mathrm{PH}$ is important in triggering investigations and avoiding misdiagnosis, or a delays in diagnosis, which is unfortunately still very common (see patient pathway, Figure 1, initial steps are characterised by misdiagnosis, causing anger, frustration and confusion to the patient, http://www.phauk.org/). ${ }^{13}$ Indeed, it is typical for PH patients to have met several physicians regarding their symptoms, before a diagnosis of $\mathrm{PH}$ is made. Once the suspicion of $\mathrm{PH}$ is raised, the diagnostic algorithm provided by international guidelines should be followed.

Transthoracic echocardiography is key for screening patients and establishing a firm clinical suspicion of PH. ${ }^{14}$ Echocardiography is widely available, cheap and easy to perform, but requires expertise in interpreting potential signs of $\mathrm{PH}$. Continuous wave Doppler measurement of peak tricuspid regurgitation velocity is recommended for assessing the probability of $\mathrm{PH}$ (Figure 2). To estimate systolic PA pressure (in the absence of pulmonary stenosis), one has to add right atrial pressure (RAP) to the tricuspid regurgitation pressure gradient. Sources of error derive from insufficient, poorly recorded tricuspid regurgitation Doppler signals and inaccurate estimation of RAP. ${ }^{15}$ Consequently, several additional echocardiographic signs have been proposed and should be sought, which relate to ventricles, the pulmonary artery, inferior vena cava and right atrium

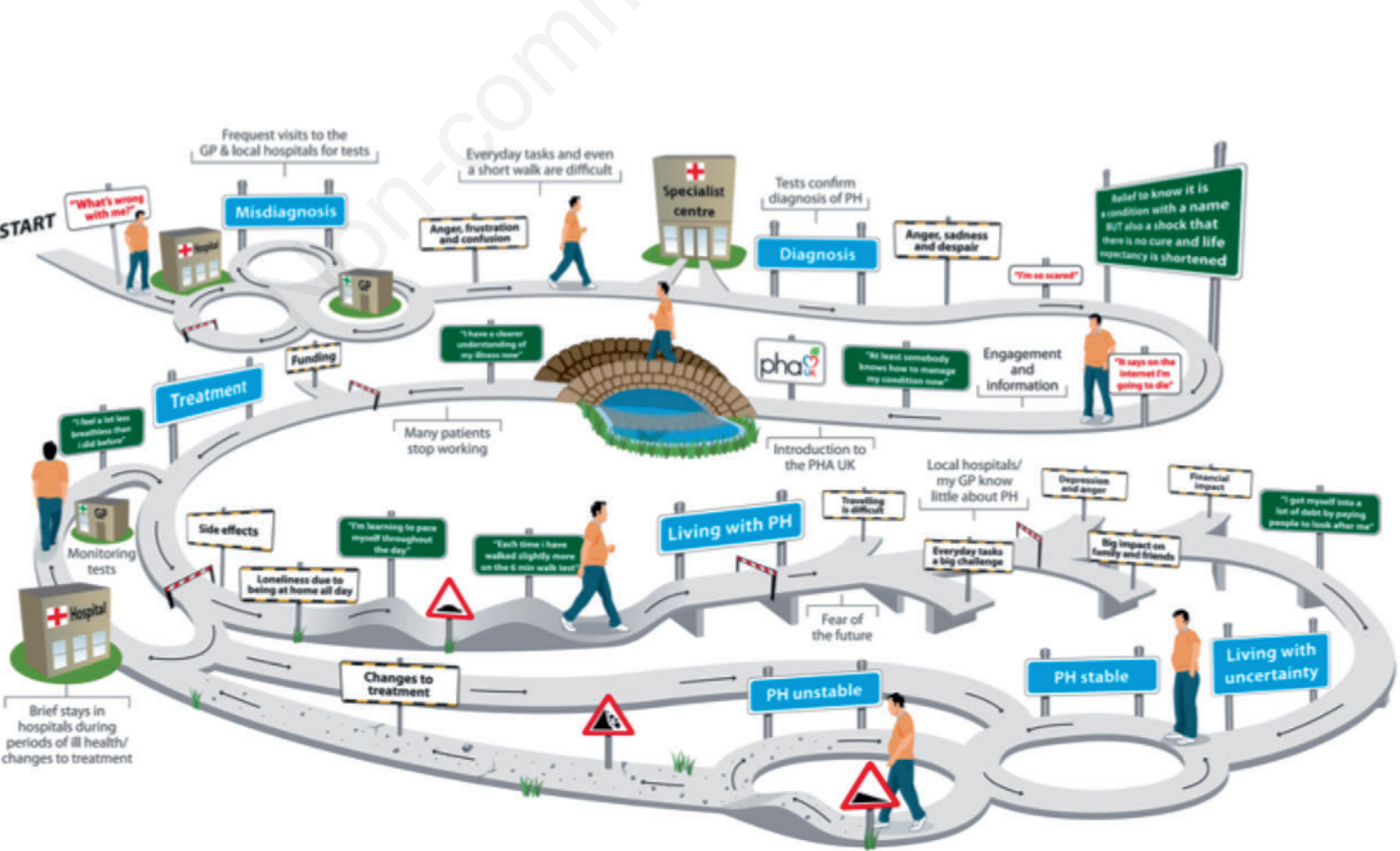

Figure 1. The pathway of the patient living with pulmonary hypertension (PH): from onset of symptoms, to diagnosis and treatment (http://www.phauk.org/). 
(Figure 2). ${ }^{1}$ Expertise is required when assessing patients with congenital heart disease, in whom the above signs may not apply. ${ }^{16}$

The diagnostic algorithm suggests that, when there is a low probability of $\mathrm{PH}$ on transthoracic echocardiography, no additional investigations are required and other causes for the symptoms should be considered (Figure 3). In patients with high or intermediate $\mathrm{PH}$ probability, further investigations are required, starting with the identification of patients with coexisting left heart disease or lung disease that are unlikely to be candidates for PAH therapies, but may benefit from expert review when signs of severe $\mathrm{PH}$ and RV dysfunction are present. Patients without

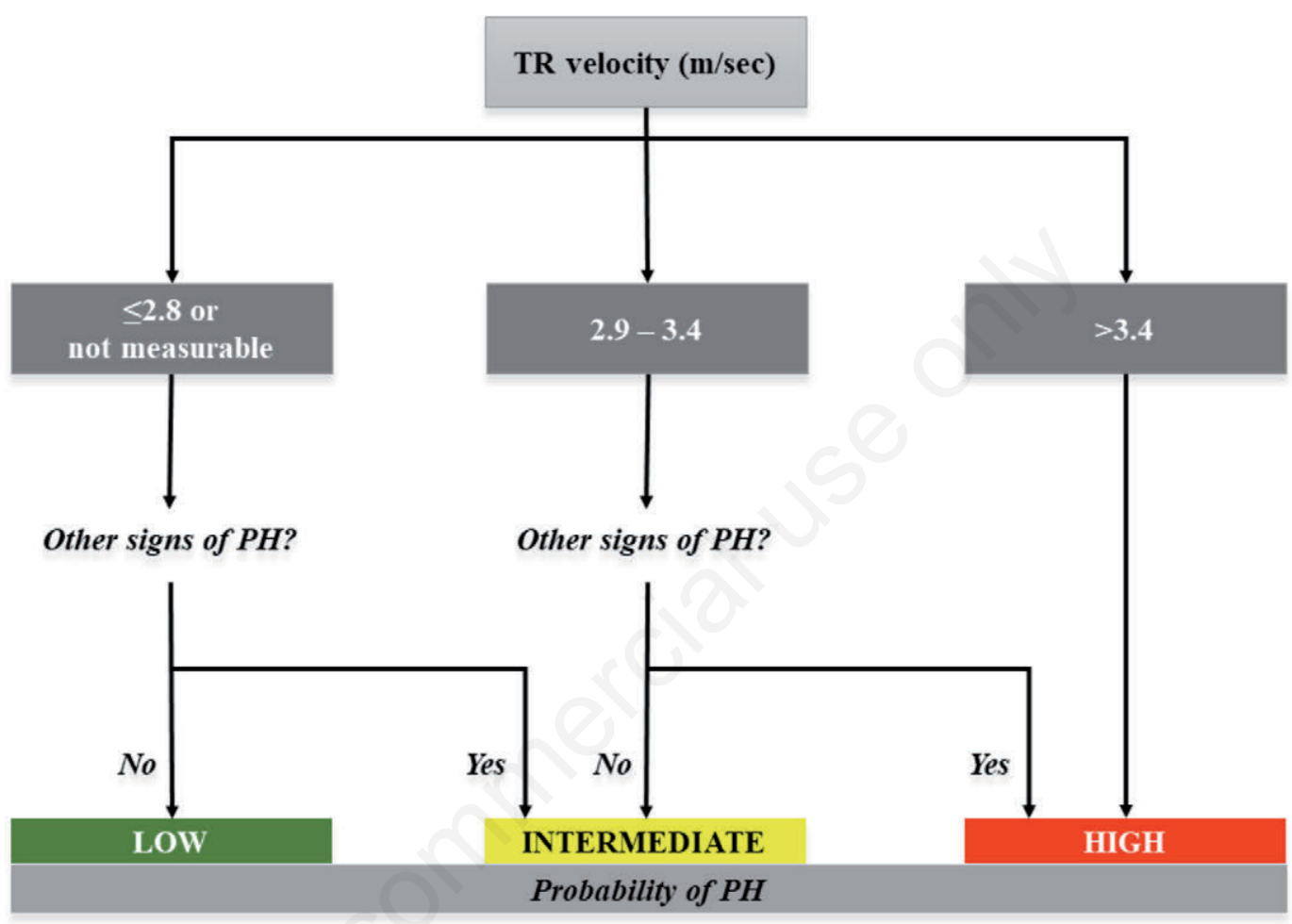

Other signs of PH

\begin{tabular}{ccc}
\hline $\begin{array}{c}\text { A } \\
\text { The ventricles }\end{array}$ & $\begin{array}{c}\text { B } \\
\text { Pulmonary artery }\end{array}$ & $\begin{array}{c}\text { C } \\
\text { Inferior vena cava } \\
\text { and right atrium }\end{array}$ \\
$\begin{array}{c}\text { RV/LV basal } \\
\text { diameter ratio }>1.0\end{array}$ & $\begin{array}{c}\text { RV outflow Doppler } \\
\text { acceleration time }<105 \mathrm{~ms} \\
\text { and/or mid-systolic } \\
\text { notching }\end{array}$ & $\begin{array}{c}\text { IVC dimension }>21 \mathrm{~mm} \text { with } \\
\text { decreased inspiratory collapse } \\
(<50 \% \text { with a sniff or }<20 \% \text { with } \\
\text { quiet inspiration) }\end{array}$ \\
$\begin{array}{c}\text { Flattening of the IVS } \\
\text { (LV eccentricity } \\
\text { index }>1.1 \text { in systole } \\
\text { and/or diastole) }\end{array}$ & $\begin{array}{c}\text { Early diastolic } \mathrm{PR} \\
\text { velocity }>2.2 \mathrm{~m} / \mathrm{s}\end{array}$ & RA area (end-systole $)>18 \mathrm{~cm}^{2}$ \\
& PA dimension $>25 \mathrm{~mm}$ & \\
\hline
\end{tabular}

Figure 2. The probability of pulmonary hypertension (PH) based on echocardiography: tricuspid regurgitation (TR) velocity and other signs of PH. RV/LV, right ventricle/left ventricle; IVC, inferior vena cava; IVS, interventricular septum; PR, pulmonary regurgitation; RA, right atrium; PA, pulmonary artery. 
left heart or significant lung disease, should be referred to a recognised high-volume expert $\mathrm{PH}$ centre for further investigations, starting with a V/Q scan to identify CTEPH patients who may be candidates for PEA. Several other investigations are recommended to identify potential causes for $\mathrm{PH}$, but the mainstay for establishing the diagnosis is cardiac catheterisation. ${ }^{1}$

The PH guidelines recommend that expert PH centres should care for at least 50 patients on PAH treatment, with at least two new PAH or CTEPH referrals per month. However, higher volumes and a wide diagnostic case-mix, with expertise in the use of all types of PAH therapies and a multidisciplinary approach to $\mathrm{PH}$ is advisable. PAH and CTEPH patients should be followed regularly in an expert centre, using multiple parameters for estimating risk, detecting disease progression and assessing the response to treatment. ${ }^{17}$

\section{Risk stratification in pulmonary arterial hypertension patients}

Risk stratification is part of the initial assessment and follow-up of PAH and CTEPH patients and is based on multiple clinical parameters, including functional variables, imaging and hemodynamic status. ${ }^{1}$ For PAH patients, a risk stratification tool is proposed, based on estimated 1-year mortality from registry data (Table 3 ). Indeed, large contemporary PH registries have provided valuable information of risk stratification. These include the US-based Registry to Evaluate Early And Long-term PAH Disease Management (REVEAL) and the French Pulmonary Hypertension Network Registry (FPHN). ${ }^{18,19}$ The REVEAL registry is a longitudinal registry, which has highlighted the importance of developing and validating multifactorial risk assessment tools. The FPHN was used to develop the French risk equation estimating survival at 3 years from diagnosis. The FPHN data was also used to estimate survival in patients with dual oral combination therapy. Notably, the expected survival of patients on initial dual oral combination therapy, using the French registry risk equation, was $97 \%$ at 1 year compared with the calculated expected survival rates of $86 \% .{ }^{20}$ Recently, Boucly et al. demonstrated that using a simple score by enumerating low-risk criteria present at diagnosis and after treatment initiation, was able to predict longterm transplant-free survival. Outcome was best in patients with $>2$ of the following: New York Heart Association (or the PH-specific World Heart Organisation) functional class I or II, 6-min walking distance $>440 \mathrm{~m}$, right atrial pressure $<8 \mathrm{mmHg}$ and cardiac index $\geq 2.5 \mathrm{~L} / \mathrm{min} / \mathrm{m}^{2}$ ). The score also worked well when replacing invasive parameters with brain natriuretic. $^{21}$ The Prospective Registry of Newly

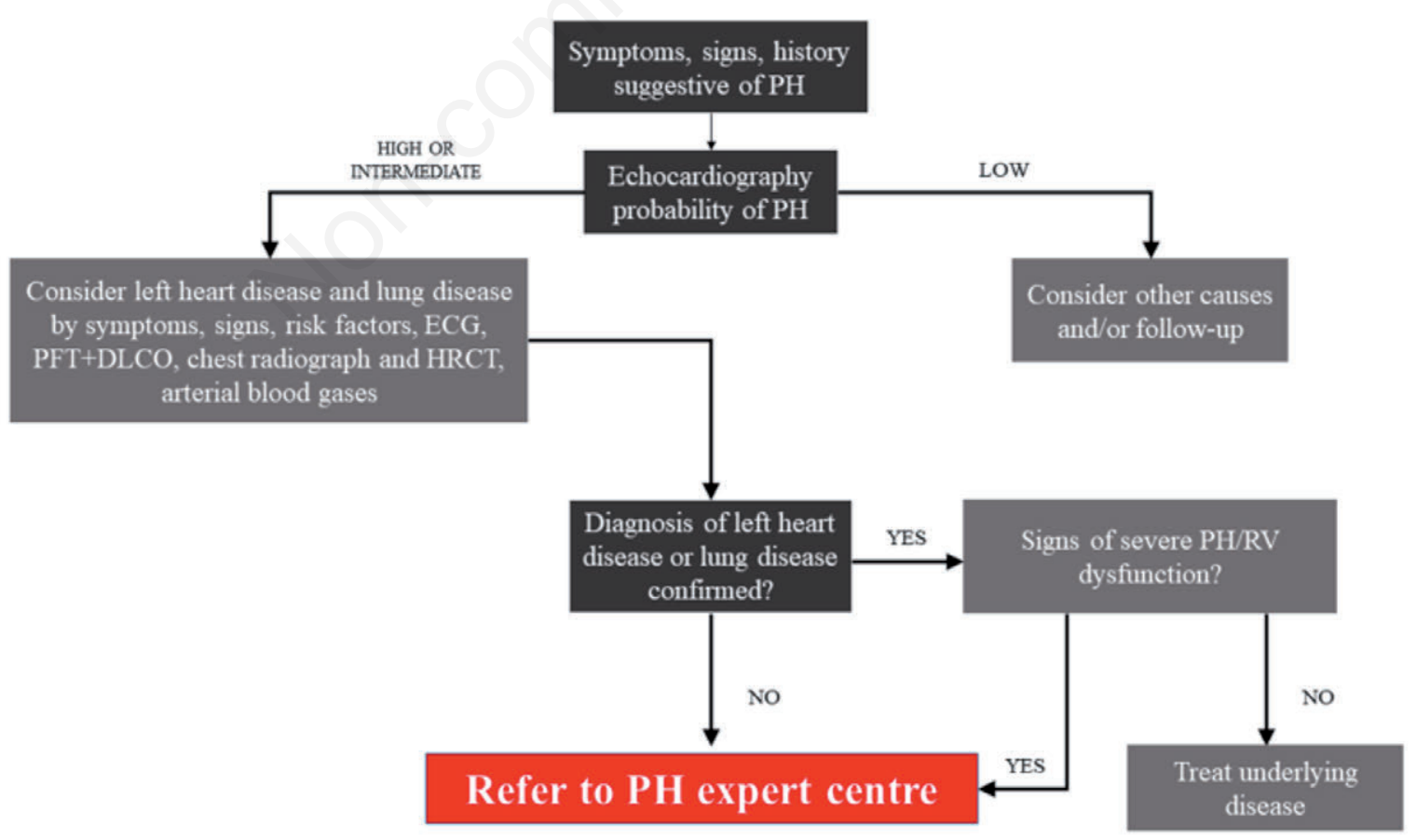

Figure 3. Diagnostic algorithm, according to the current pulmonary hypertension (PH) guidelines. ECG, electrocardiogram; PFT+DLCO, pulmonary function test+diffusing capacity of the lung for carbon monoxide; HRCT, high-resolution computed tomography; RV, right ventricular. 
Initiated Therapies for Pulmonary Hypertension (COMPERA) also confirmed that an abbreviated version of the risk assessment strategy proposed by the $\mathrm{PH}$ guidelines is accurate in estimating mortality in patients with PAH. ${ }^{22}$

Risk stratification tools should always be combined with clinical judgment by the PH expert, striving to achieve the lowest possible risk status, through aggressive management of the disease. $\mathrm{PH}$ guidelines recommend initial combination therapy in high risk patients, and initial oral monotherapy or combination therapy for low or intermediate risk patients. ${ }^{1,21}$ Those at very high risk should be considered for prostanoid therapy.

\section{Therapy}

\section{Pulmonary arterial hypertension}

All forms of PAH share a common pathophysiology, characterized by endothelial dysfunction, abnormal intimal and smooth muscle proliferation and reduced apoptosis, resulting in elevated pulmonary pressures and right ventricular failure. Research in PAH has focused on identifying molecular targets for inducing vasodilation, inhibiting and reversing inflammation, proliferation, fibrotic changes and remodelling within the pulmonary vasculature. Currently used PAH therapies target one of the three major pathways involved in development and progression of $\mathrm{PAH}$ : the endothelin, the prostacyclin and the nitric oxide pathways (Figure 4). Most randomized controlled trials have included $\mathrm{PAH}$ and CTD PAH patients, with a limited number of HIVrelated, drug-related and repaired CHD patients. While in the past initial drug monotherapy was recommended in treatment-naïve patients, there is recent evidence to support upfront or early sequential combination therapy, with 2 drugs acting on the nitric oxide and endothelin pathways. ${ }^{1}$ The Study with an Endothelin Receptor Antagonist in Pulmonary Arterial Hypertension to Improve Clinical Outcome (SERAPHIN) trial was a double-blind, event-driven phase III randomized controlled trial designed to investigate the effects of long-term treatment with macitentan (endothelin receptor antagonist, ERA) compared with placebo in patients with PAH using a composite primary endpoint of morbidity and mortality. ${ }^{23}$ It was the first long-term trial in PAH and the first trial to use a clinically relevant composite primary endpoint. It has provided robust evidence that combination therapy with macitentan and a

Table 3. Risk assessment in pulmonary arterial hypertension according with the current guidelines.

\begin{tabular}{|c|c|c|c|}
\hline $\begin{array}{l}\text { Determinants of prognosis } \\
\text { (estimated 1-year mortality) }\end{array}$ & Low risk & Intermediate risk & High risk \\
\hline \multicolumn{4}{|c|}{ Functional variables } \\
\hline Clinical signs of right heart failure & Absent & Absent & Present \\
\hline Progression of symptoms & No & Slow & Rapid \\
\hline Syncope & No & Occasional syncope & Repeated syncope \\
\hline WHO functional class & I, II & III & IV \\
\hline 6MWD & $>440 \mathrm{~m}$ & $165-440 \mathrm{~m}$ & $<165 \mathrm{~m}$ \\
\hline Cardiopulmonary exercise testing & $\begin{array}{c}\text { Peak } \mathrm{VO}_{2} \\
15 \mathrm{~mL} / \mathrm{min} / \mathrm{kg} \\
(>65 \% \text { pred. }) \\
\mathrm{VE} / \mathrm{VCO}_{2} \text { slope }<36\end{array}$ & $\begin{array}{c}\text { Peak } \mathrm{VO}_{2} \\
11-15 \mathrm{~mL} / \mathrm{min} / \mathrm{kg} \\
(35-65 \% \text { pred.) } \\
\mathrm{VE} / \mathrm{VCO}_{2} \text { slope } 36-44.9\end{array}$ & $\begin{array}{c}\text { Peak } \mathrm{VO}_{2} \\
<11 \mathrm{~mL} / \mathrm{min} / \mathrm{kg} \\
(<35 \% \text { pred. }) \\
\mathrm{VE} / \mathrm{VCO}_{2} \text { slope } \geq 45\end{array}$ \\
\hline \multicolumn{4}{|c|}{ Imaging } \\
\hline Echocardiography and CMR & $\begin{array}{c}\text { RA area }<18 \mathrm{~cm}^{2} \\
\text { No pericardial effusion }\end{array}$ & $\begin{array}{l}\text { RA area } 18-26 \mathrm{~cm}^{2} \\
\text { No or minimal, } \\
\text { pericardial effusion }\end{array}$ & $\begin{array}{l}\text { RA area }>26 \mathrm{~cm}^{2} \\
\text { Pericardial effusion }\end{array}$ \\
\hline \multicolumn{4}{|c|}{ Haemodynamic status } \\
\hline Right heart catheterization & $\begin{array}{c}\mathrm{RAP}<8 \mathrm{mmHg} \\
\mathrm{CI} \geq 2.5 \mathrm{~L} / \mathrm{min} / \mathrm{m}^{2} \\
\mathrm{SvO}_{2}>65 \%\end{array}$ & $\begin{array}{c}\text { RAP 8-14 mmHg } \\
\text { CI } 2.0-2.4 \mathrm{~L} / \mathrm{min} / \mathrm{m}^{2} \\
\mathrm{SvO}_{2} 60-65 \%\end{array}$ & $\begin{array}{c}\mathrm{RAP}>14 \mathrm{mmHg} \\
\mathrm{CI}<2.0 \mathrm{~L} / \mathrm{min} / \mathrm{m}^{2} \\
\mathrm{SvO}_{2}<60 \%\end{array}$ \\
\hline \multicolumn{4}{|c|}{ Biochemical } \\
\hline NT-proBNP plasma levels & $\begin{array}{c}\mathrm{BNP}<50 \mathrm{ng} / \mathrm{L} \\
\text { NT-proBNP }<300 \mathrm{ng} / \mathrm{L}\end{array}$ & $\begin{array}{c}\text { BNP 50-300 ng/L } \\
\text { NT-proBNP 300-1400 ng/L }\end{array}$ & $\begin{array}{c}\text { BNP }>300 \mathrm{ng} / \mathrm{L} \\
\text { NT-proBNP }>1400 \mathrm{ng} / \mathrm{L}\end{array}$ \\
\hline
\end{tabular}

WHO, World Health Organization; 6MWD, 6-minute walking distance; CMR, cardiac magnetic resonance; RA, right atrium; RAP, right atrium pressure; CI, cardiac index. 
phosphodiesterae-5 inhibitor (PDE-5i) is beneficial on the clinical outcome of PAH patients. The Ambrisentan and Tadalafil in Patients with Pulmonary Arterial Hypertension (AMBITION) trial established the value of upfront combination therapy in treatment naïve patients. This study demonstrated that ambrisentan (an ERA) and tadalafil (a PDE-5i) reduced the risk of clinical failure events by $50 \%$, with a significant improvement in 6MWT distance and NTproBNP. ${ }^{24}$ These two recent trials established the role of upfront or early sequential combination therapy, as recommended in the guidelines.

Prostanoids, especially intravenous or subcutaneous compounds, are currently used as thirdline treatment, unless the patient presents with advanced disease, in functional class IV. Until recently, only inhaled, intravenous or subcutaneous drugs acting on the prostacyclin pathway were available, and were associated with significant sideeffects and discomfort related to the mode of administration (e.g. line infections, local pain, etc.). Selexipag, an oral selective prostacyclin receptor agonist, has recently become available and the benefits of double and triple combination therapy with an ERA and/or a PDE-5i, were recently reported in the Prostacyclin (PGI2) Receptor Agonist In Pulmonary Arterial Hypertension (GRIPHON) trial. ${ }^{25}$ Selexipag reduced morbidity and mortality in this $\mathrm{PAH}$ population. GRIPHON was the first large randomized controlled trial to support the use of triple combination therapy in $\mathrm{PAH}$, which may be considered in patients who fail to respond to dual combination therapy, patients presenting with advanced disease, and those referred to transplantation.

In patients with PAH-CHD, the strongest evidence on PAH therapy is for bosentan (an ERA) and tadalafil (a PDE-5i). ${ }^{26,27}$ The Bosentan Randomized Trial of Endothelin Antagonist Therapy-5 (BREATHE-5) study showed a significant improvement in hemodynamic and exercise capacity with bosentan, without adversely affecting systemic arterial oxygen saturations. ${ }^{26}$ The recently concluded Effects of Macitentan on Exercise Capacity in Subjects With Eisenmenger Syndrome (MAESTRO) trial failed to demonstrate a significant improvement in 6MWT distance, even though an improvement in PVR and BNP was reported. ${ }^{28}$

\section{Pulmonary hypertension management in other diagnostic subgroups}

PAH therapies should not be used in patients with post-capillary PH (Group 2, left heart disease) and there is no evidence for those with lung disease (Group 3). Treatment of the underlying condition is strongly recommended (e.g. LV dysfunction, valve disease, sleep apnoea, long-term oxygen

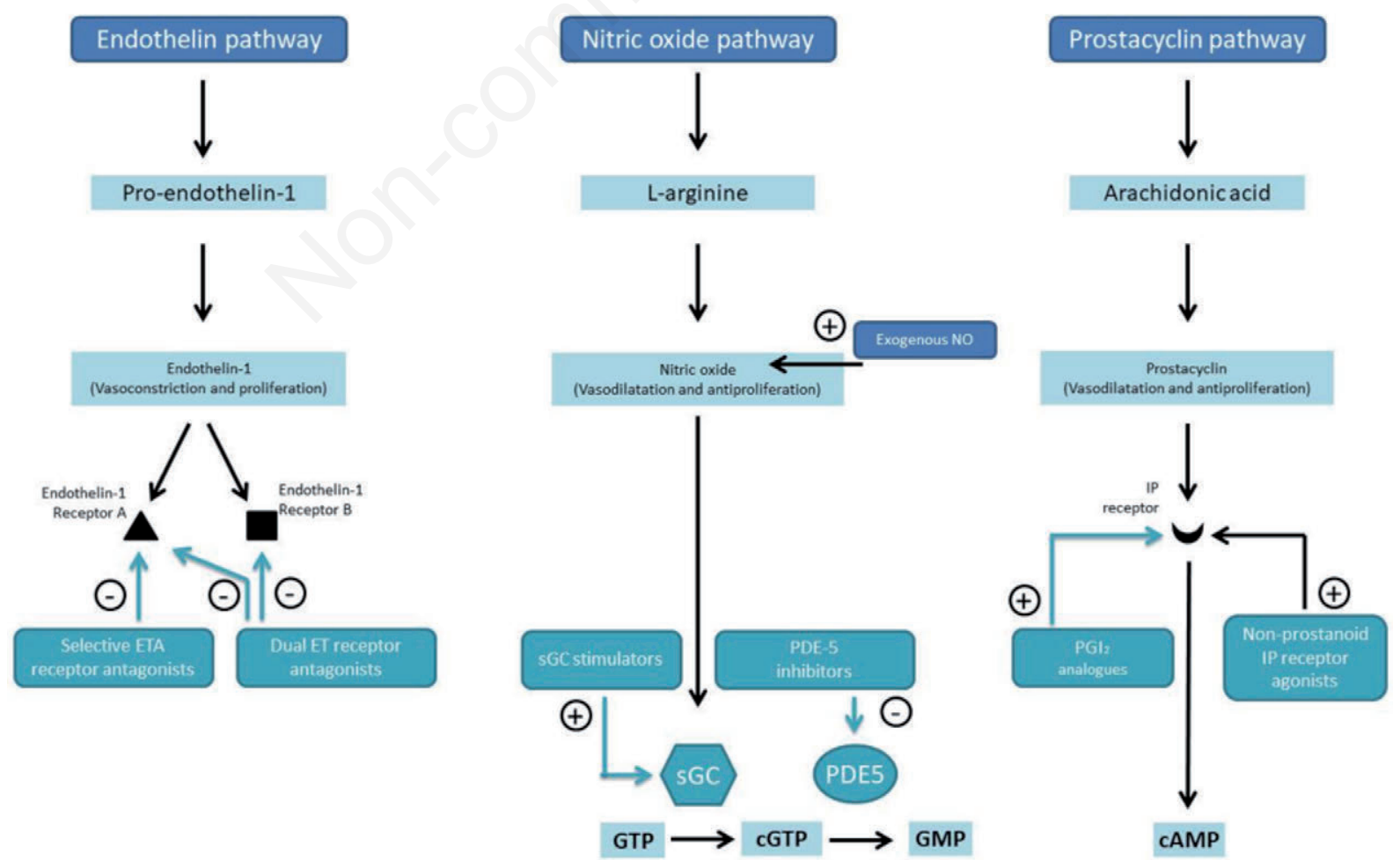

Figure 4. The three major pathways involved in the development and progression of pulmonary arterial hypertension. 
supplementation in COPD) and is likely to improve the severity of PH. CTEPH is the only type of precapillary $\mathrm{PH}$ that can be cured through PEA in eligible patients. Indeed, referral of all CTEPH patients to a PEA centre at the time of diagnosis for advice on surgery is mandatory. Inoperable patients may benefit from balloon pulmonary angioplasty (Figure 5).

If patients are operable, PEA can lead to a substantial improvement in symptoms and a return to a normal life expectancy and quality of life. Inoperable patients or patients with an unacceptable surgical risk/benefit ratio or persistent $\mathrm{PH}$ after PEA, may be candidates for PAH therapy (most evidence for riociguat and macitentan, but PDE5-Is are often used). ${ }^{29,30}$

In the United Kingdom, the long-term survival post PEA at 10 years is $72 \%$ whereas patients who choose not to proceed to surgery, have a similar mortality to non-operable disease. ${ }^{31}$ For this reason, it is important to obtain the opinion of an expert PEA team at diagnosis.

\section{Quality of life in pulmonary hypertension}

$\mathrm{PH}$ is a progressive debilitating condition that negatively affects patients' quality of life (QoL), by impacting on their ability to perform physically demanding everyday life activities: PH can affect their

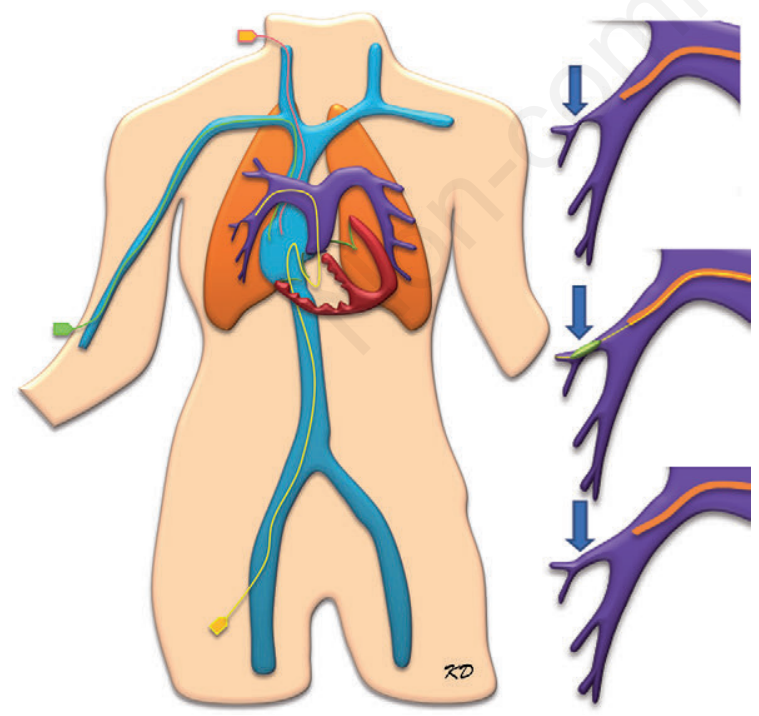

Figure 5. Balloon pulmonary angioplasty for chronic thromboembolic disease. Stenoses in peripheral vessels can be treated using balloon angioplasty: while no stenting is required, attention should be made to avoid vessel damage (and hemoptysis, which can be catastrophic) and reperfusion edema. For this reason, numerous procedures (average 3-4) are typically required, treating one segment each time. ability to work (whether in a physically active job or just commuting to work), their ability to play with or look after their children, maintain a healthy sexual relation and be socially active. Moreover, frequent follow-up appointments, repeat hospitalisations and laborious treatments with important side-effects (e.g. prostanoids, need for long-term oxygen) can have a psychological impact on patients with $\mathrm{PH}$; regular assessment of QoL is as important as assessing exercise capacity or hemodynamics.

There are currently 2 disease $(\mathrm{PH})$-specific questionnaires: the Cambridge Pulmonary Hypertension Outcome Survey (CAMPHOR) score has been used for several year and addresses several aspects of the disease, but is quite lengthy (65 items), which limits its use in routine clinical practice. ${ }^{32} \mathrm{~A} 10$ question QoL questionnaire, called emPHasis 10 (E10), was recently designed specifically for use in routine clinical practice. ${ }^{33,34}$ It was derived from three previous PH scores: the Minnesota Living with Heart Failure Questionnaire (MLHFQ) modified for PH, the Dyspnoea-12 (D-12) that reflects the physical perception and emotional effects of dyspnoea, and the Hospital Anxiety and Depression scale (HAD), which addresses psychological distress. ${ }^{34,35}$ Each of the 10 questions is scored in a semantic 6-point scale (from 0 to 5), for a total maximum score of 50. The E10 score is currently used in most centres in the UK and has been translated into several languages (Figure 6).

\section{The organisation of pulmonary hypertension care in United Kingdom and Ireland}

In the UK and Ireland, a limited number of specialist centres have been designated as National Pulmonary Hypertension Centres, and are allowed to manage and prescribe PAH therapies, given the rarity of the disorder, its complexity and the cost of therapy. ${ }^{1}$ There are currently 8 National PH Centres, working collaboratively to advise policy makers. PH centres are required to meet a strict set of standards for service delivery and are regularly inspected for compliance.

A multidisciplinary approach to $\mathrm{PH}$ is essential: the $\mathrm{PH}$ team should be composed of at least two senior physicians dedicated to $\mathrm{PH}$, clinical nurse specialists, radiologists and cardiologists with expertise in $\mathrm{PH}$ imaging, echocardiography and RHC. PH centres should have access to several other services, including psychology, genetics, lung transplantation, adult CHD, high-risk anaesthetics and surgery, pregnancy and heart disease.

Each centre is expected to develop a network of Shared Care centres that allow management of patients closer to home, yet are responsible for ensuring high quality care, collecting data for the National PH audit, ensuring equitable access for patients and promoting 


\section{em $P$ asis $10^{\circ}$}

This questionnaire is designed to determine how pulmonary

hypertension $(\mathrm{PH})$ affects your life. Please answer every question

by placing a tick over the ONE NUMBER that best describes your recent experience of living with $\mathrm{PH}$.

For each item below, place a tick $(\checkmark)$ in the box that best describes your experience.

I am not frustrated by my breathlessness

Being breathless never interrupts my conversations

I do not need to rest
during the day

I do not feel exhausted

I have lots of energy

\section{When I walk up one flight of} stairs I am not breathless

I am confident out in public places/crowds despite my $\mathrm{PH}$
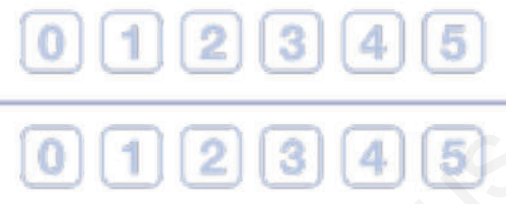

(0)(1)(2) (3) (4) (5) during the day

I always feel exhausted

I have no energy at all

When I walk up one flight of stairs I am very breathless

I am not confident at all in public places/crowds because of $\mathrm{my} \mathrm{PH}$

$\mathrm{PH}$ does not control my life $010 \mathrm{2}, 5 \mathrm{PH}$ completely controls my life

I am independent 05035 I 5 I am completely dependent

I never feel like a burden

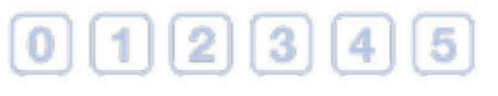

I always feel like a burden
Date:

MANCHESTER

Figure 6. The emPHasis10 score questionnaire. Freely available from PHA-UK. 
education and research. ${ }^{17}$ Shared care networks are important for facilitating access to specialist care across the country, reducing costs and discomfort relating to travel, especially in patients with significant disease. Moreover, patients are known to local services, that can contact the tertiary PH centre for advice when patients present decompensated, with an arrhythmia or other emergency. ${ }^{36}$

All designated centres in the UK are expected to manage at least 250 patients per annum with PAH or CTEPH. Participation in the National Audit is a legal requirement, allowing regular assessment of the services at National and local level, with regards to compliance with national standards. ${ }^{1}$ The National Audit also provides epidemiological information for future planning, allocation of funds, and understanding the outcomes of patients with $\mathrm{PH}^{37,38}$

\section{Conclusions}

PH is a progressive disease with a high mortality and mobility and should be part of the differential diagnosis of all patients presenting with dyspnoea and exercise intolerance of unclear cause. Prompt referral to specialist $\mathrm{PH}$ services is essential, ensuring rapid expert assessment and management for all patients. A limited number of National PH Centres, in proportion to the population, with a wider network of associated Shared Care PH centres, can result in an optimal balance of providing timely expert care as close to the patients' home as possible.

\section{References}

1. Galiè N, Humbert M, Vachiery J-L, et al. 2015 ESC/ERS Guidelines for the diagnosis and treatment of pulmonary hypertensionThe Joint Task Force for the Diagnosis and Treatment of Pulmonary Hypertension of the European Society of Cardiology (ESC) and the European Respiratory Society (ERS): Endorsed by: Association for European Paediatric and Congenital Cardiology (AEPC), International Society for Heart and Lung Transplantation (ISHLT). Eur Heart J 2016;37:67-119.

2. Kheyfets VO, Schafer M, Podgorski CA, et al. 4D magnetic resonance flow imaging for estimating pulmonary vascular resistance in pulmonary hypertension. J Magn Reson Imaging JMRI 2016;44:914-22.

3. Asari Y, Yamasaki Y, Tsuchida K, et al. Hemodynamic heterogeneity of connective tissue disease patients with borderline mean pulmonary artery pressure and its distinctive characters from those with normal pulmonary artery pressure: a retrospective study. Clin Rheumatol 2018 [Epub ahead of print].

4. Girerd B, Weatherald J, Montani D, Humbert M. Heritable pulmonary hypertension: from bench to bedside. Eur Respir Rev Off J Eur Respir Soc 2017;26:145.

5. McGee M, Whitehead N, Martin J, Collins N. Drug- associated pulmonary arterial hypertension. Clin Toxicol Phila Pa 2018 [Epub ahead of print].

6. Georgiopoulou VV, Kalogeropoulos AP, Borlaug BA, et al. Left ventricular dysfunction with pulmonary hypertension: Part 1: epidemiology, pathophysiology, and definitions. Circ Heart Fail 2013;6:344-54.

7. Bax S, Bredy C, Kempny A, et al. A stepwise composite echocardiographic score predicts severe pulmonary hypertension in patients with interstitial lung disease. ERJ Open Res 2018 [Epub ahead of print].

8. Corte TJ, Keir GJ, Dimopoulos K, et al. Bosentan in pulmonary hypertension associated with fibrotic idiopathic interstitial pneumonia. Am J Respir Crit Care Med 2014;190:208-17.

9. Kumar N, Price LC, Montero MA, et al. Pulmonary tumour thrombotic microangiopathy: unclassifiable pulmonary hypertension? Eur Respir J 2015;46:1214-7.

10. Klok FA, Delcroix M, Bogaard HJ. Chronic thromboembolic pulmonary hypertension from the perspective of patients with pulmonary embolism. J Thromb Haemost JTH 2018 [Epub ahead of print].

11. Dimopoulos K, Kempny A, Alonso-Gonzalez R, Wort SJ. Percutaneous transluminal pulmonary angioplasty for the treatment of chronic thromboembolic pulmonary hypertension: Challenges and future directions. Int J Cardiol 2015;187:401-3.

12. Inami $\mathrm{T}$, Kataoka $\mathrm{M}$, Ishiguro $\mathrm{H}$, et al. Percutaneous transluminal pulmonary angioplasty for chronic thromboembolic pulmonary hypertension with severe right heart failure. Am J Respir Crit Care Med 2014;189:1437-9.

13. Armstrong I, Rochnia N, Harries C, et al. The trajectory to diagnosis with pulmonary arterial hypertension: a qualitative study. BMJ Open 2012;2:e00806.

14. D'Alto M, Dimopoulos K, Budts W, et al. Multimodality imaging in congenital heart disease-related pulmonary arterial hypertension. Heart Br Card Soc 2016;102:910-8.

15. McCann C, Gopalan D, Sheares K, Screaton N. Imaging in pulmonary hypertension, part 1: clinical perspectives, classification, imaging techniques and imaging algorithm. Postgrad Med J 2012;88:271-9.

16. Dimopoulos K, Wort SJ, Gatzoulis MA. Pulmonary hypertension related to congenital heart disease: a call for action. Eur Heart J 2014;35:691-700.

17. Corris PA. The UK National Pulmonary Hypertension Service, Registry and Research Collaboration. Glob Cardiol Sci Pract 2015;2015:37.

18. Barst RJ, Chung L, Zamanian RT, et al. Functional class improvement and 3-year survival outcomes in patients with pulmonary arterial hypertension in the REVEAL Registry. Chest 2013;144:160-8.

19. Benza RL, Miller DP, Gomberg-Maitland M, et al. Predicting survival in pulmonary arterial hypertension: insights from the Registry to Evaluate Early and LongTerm Pulmonary Arterial Hypertension Disease Management (REVEAL). Circulation 2010;122:164-72.

20. Raina A, Humbert M. Risk assessment in pulmonary arterial hypertension. Eur Respir Rev Off J Eur Respir Soc 2016;25:390-8.

21. Boucly A, Weatherald J, Savale L, et al. Risk assessment, prognosis and guideline implementation in pulmonary arterial hypertension. Eur Respir J 2017 [Epub ahead of print]. 
22. Hoeper MM, Kramer T, Pan Z, et al. Mortality in pulmonary arterial hypertension: prediction by the 2015 European pulmonary hypertension guidelines risk stratification model. Eur Respir J 2017 [Epub ahead of print].

23. Pulido T, Adzerikho I, Channick RN, et al. Macitentan and morbidity and mortality in pulmonary arterial hypertension. N Engl J Med 2013;369:809-18.

24. Galiè N, Barberà JA, Frost AE, et al. Initial Use of Ambrisentan plus Tadalafil in Pulmonary Arterial Hypertension. N Engl J Med 2015;373:834-44.

25. Sitbon O, Channick R, Chin KM, et al. Selexipag for the treatment of pulmonary arterial hypertension. N Engl J Med 2015;373:2522-33.

26. Galiè N, Beghetti M, Gatzoulis MA, et al. Bosentan therapy in patients with Eisenmenger syndrome: a multicenter, double-blind, randomized, placebocontrolled study. Circulation 2006;114:48-54.

27. Mukhopadhyay S, Nathani S, Yusuf J, et al. Clinical efficacy of phosphodiesterase-5 inhibitor tadalafil in Eisenmenger syndrome-a randomized, placebocontrolled, double-blind crossover study. Congenit Heart Dis 2011;6:424-31.

28. Galie N, Landzberg M, Beghetti M, et al. Evaluation of macitentan in patients with Eisenmenger syndrome: results from the randomised controlled MAESTRO study. Eur Heart J [Internet] 2017 Aug 1 [cited 2017 Dec 3];38(suppl_1). Available from: https://academic.oup. com/eurheartj/article/38/suppl_1/ehx493.P5462/4086822

29. Ghofrani H-A, D'Armini AM, Grimminger F, et al. Riociguat for the treatment of chronic thromboembolic pulmonary hypertension. N Engl J Med 2013;369:319-29.

30. Ghofrani H-A, Simonneau G, D'Armini AM, et al. Macitentan for the treatment of inoperable chronic thromboembolic pulmonary hypertension (MERIT-1): results from the multicentre, phase 2, randomised, double-blind, placebo-controlled study. Lancet Respir Med 2017;5:785-94.

31. Cannon JE, Su L, Kiely DG, et al. Dynamic risk stratification of patient long-term outcome after pulmonary endarterectomy: results from the United Kingdom National Cohort. Circulation 2016;133:1761-71.

32. Meads DM, McKenna SP, Doughty N, et al. The responsiveness and validity of the CAMPHOR Utility Index. Eur Respir J 2008;32:1513-9.

33. Foster E, Guillen A, Lara K, et al. Linguistic validation of the emphasis-10 questionnaire: a patient-reported outcome instrument for assessing qol in pulmonary hypertension $(\mathrm{Ph})$. Value Health $\mathrm{J}$ Int Soc Pharmacoeconomics Outcomes Res 2015;18:A744.

34. Yorke J, Corris P, Gaine S, et al. emPHasis-10: development of a health-related quality of life measure in pulmonary hypertension. Eur Respir J 2014;43:1106-13.

35. Mogle J, Buck H, Zambroski C, et al. Cross-validation of the minnesota living with heart failure questionnaire. J Nurs Scholarsh Off Publ Sigma Theta Tau Int Honor Soc Nurs 2017;49:513-20.

36. Price LC, Dimopoulos K, Marino P, et al. The CRASH report: emergency management dilemmas facing acute physicians in patients with pulmonary arterial hypertension. Thorax 2017;72:1035-45.

37. National Audit of Pulmonary Hypertension 8th Annual Report - NHS Digital [Internet]. [cited 2018 Mar 10]. Available from: https://digital.nhs.uk/catalogue/PUB30128

38. Tulloh R, Dimopoulos K, Condliffe R, et al. Management of adults with congenital heart disease and pulmonary arterial hypertension in the UK: survey of current practice, unmet needs and expert commentary. Heart Lung Circ 2017 [Epub ahead of print]. 